Agro-Science Journal of Tropical Agriculture, Food, Environment and Extension Volume 20 Number 2 (April 2021) pp. 14 - 19

ISSN 1119-7455

\title{
CONSUMPTION BEHAVIOUR ANALYSES OF CASSAVA PRODUCTS AMONG RURAL HOUSEHOLD IN EBONYI STATE, NIGERIA
}

\author{
${ }^{* 1}$ Okoye F.U., ${ }^{2}$ Okoye A.C. and ${ }^{1}$ Umeh S.I. \\ ${ }^{1}$ Federal College of Agriculture, Ishiagu, Ebonyi State, Nigeria \\ ${ }^{2}$ National Root Crops Research Institute, Umudike, P.M.B. 7006 Umuahia, Abia State, Nigeria
}

${ }^{*}$ Corresponding author's email: uzofranca2@yahoo.com

\begin{abstract}
This study provides empirical evidence on consumption behavior of cassava products among households in Ebonyi State, Nigeria. A multistage sampling technique was employed to collect data from 120 households using structured questionnaire. The data were analyzed using descriptive statistics, ordered Probit and Spearman correlation models. The study finds garri, fufu (pounded cassava) and tapioca as the three major cassava products consumed while rice, yam and beans as three the major substitute of garri by the households in the area. The households preferred garri over other cassava products as the factors of household choice, nutritional value and availability. The coefficient for age was negative while coefficients of cost of cassava products, marital status and household size were positively related to choice of cassava products consumed in the study area. The study therefore recommended for policies that will effectively promote cassava product consumption should emphasize on the adult population and household size.
\end{abstract}

Key words: Choice, decision, garri, ordered Probit

\section{INTRODUCTION}

Cassava is the Nigerian most important staple food in terms of per capita calories consumed and a major source of calorie for roughly two out of every five Nigerian households (Onyemauma, 2010). It ranks very high among crops that convert the greatest amount of energy into soluble carbohydrate per unit of area. Among the starchy staples, cassava gives a carbohydrate production of $40 \%$ higher than the rice and $25 \%$ more than maize (Theodory et al., 2014). In some countries, cassava is consumed daily and sometimes more than once a day. Cassava (Manihot esculentacrantz) is a versatile commodity crop with numerous uses and by-products and serves both as food and feed (Ogunniyi, 2011). It is also available to low-income rural households in the form of simple food products (for example, dried roots and leaves) which are significantly cheaper than grains. Cassava has several other advantages over other food crops (like rice, maize and other grains) as it can thrive in areas where there is a degraded resource base, uncertain rainfall and weak marginalized market structure. Also, Nweke et al. (2002) indicated five major roles of cassava as famine crops, rural staple food, and cash crop for urban consumption, industrial raw materials and earner of foreign exchange.

The main product from cassava, the fresh cassava roots cannot be stored for long as they are bulky with about $70 \%$ moisture content and contain varying amount of cyanide which is toxic to humans and animals. Cassava are then processed to increase the shelf life of the products, facilitate transportation and marketing, reduce cyanide content, improve palatability, and the nutritional status through fortification with other rich crops to reduce food losses and stabilize seasonal fluctuations in the supply of the crop (Ogunniyi, 2011). Numerous products have been developed for cassava in different parts of the world and these results in the production and consumption of a wide variety of food products (Arua, 2019). Nweke et al. (2002) outlined food products from cassava as garri, fufu (pounded cassava), tapioca, African salad, flour for bakery; feed and starch etc. and are important chains for cassava development in Nigeria. Ezeh et al. (2011) noted that the high demand generated from the major products: garri, fufu, flour to mention but a few, cassava currently plays a vital role in crop combination of most farmers. According to Nweke et al. (2002) cassava products such as garri and flour for bakery are the most lucrative in the most countries of the world. Although consumption of the products varies among tribes, location and culture, it depends on income, relatively price, taste preference, etc. Cassava is consumed by both the rich and the poor especially when processed into food products that will suit the taste and needs of the people. 
However, people behave differently in selection and consumption of crops with different food forms like cassava. Studying consumer behavior therefore becomes necessary to examine the factors that influence decision and finally consumption. Barnett (2003) noted that consumer behavior is the study of how, when and why people buy what they buy (in other words eat what they eat). It attempts to explain the buyer decision-making process both individually and in groups, the theory of consumer behaviour assumes that a consumer is rational and aims at attaining the highest possible satisfaction given his income and the prevailing market prices. He attempts spending his income in a way that gives him maximum satisfaction (Barnett, 2003). In Nigeria, cassava is a marginalized crop in food policy debate and burden with the stigma of being an inferior, ill-suited and un-competiveness with the glamour crop such as rice and wheat (Onyemauwa, 2010). Many food policy analysts assumed that cassava as inferior food because it is assumed that its per capita consumption will decline with an increase in per capita income (Nweke et al., 2002). An individual's decision on what range and types of food to consume is influenced greatly by income and other factors such as socio-economic variables.

It is therefore imperative to actually balance the consumption behaviour of cassava product with respect to this assumption. This study therefore, analyzed the consumption behaviour of cassava products among rural households in Ebonyi state with the following objectives; to identify common cassava product consumed and its substitutes, identify factors determining the consumption of preferred cassava products and factors influencing the choice of consumption pattern of cassava products in the study area.

\section{MATERIALS AND METHODS}

The study was conducted in Ebonyi State in South East, Nigeria. The state lies approximately between $7^{\circ} 30^{\prime} \mathrm{E}$ and $5^{\circ} 40^{\prime} \mathrm{N}$ with a land mass of approximately 5932 square kilometers and population of $1,453,882$ persons (NPC, 2006). The State is made up of 13 local government areas and further divided into three agricultural zones namely Ebonyi North, Central and South zones. The major crops produced were rice, yam, cocoyam, maize, cassava, groundnut, vegetables and fruits. A multistage design that involved random sampling technique was employed in the selection of respondents for the study. The first stage involved random selection of two agricultural zones (Ebonyi North and Central) from the three zones in the state. The second stage involved random selection of two LGA from the two zones selected giving a total of four LGAs, thirdly, three communities from each LGA were randomly selected to give 12 communities, and finally, 10 households from each 12 communities were randomly selected from a sampling frame obtained from the National Population Commission for the areas to give a sample size of 120 respondents for the study. The sampling frame used was a list of household units in the area. Cross sectional data were collected in 2019 using structured questionnaire. Data collected ranged from the socio-economic variables of the respondents, consumption pattern on cassava, cassava substitute and reasons for consuming each cassava products.

The study used descriptive statistics, ordered Probit and Correlation coefficient models. Probability of a household's choice of consumption was estimated using ordered Probit model as in equations 1 and 2 . In the ordered Probit model, the dependent variable (cassava product) was defined as the household's choice to consume three different cassava products as garri, fufu and tapioca (the three highest consumed cassava products identified in the study area). This was coded as binary variables- 1,2 and 3 . Given that the dependent variable has more than two alternatives from among which the decision maker has to choose, the study employed ordered Probit model because of its documented superiority and ease of computation (Greene, 2002).

Ordered Probit ${ }_{i}^{\text {(garri, fufu, tapioca) }}-\mathrm{b}_{0}+\mathrm{b}_{\mathrm{i}} \mathrm{X}_{\mathrm{i}}+\mathrm{u}_{\mathrm{i}} .$. (1)

where Ordered Probit ${ }_{i}$ (garri, fufu, tapioca) is household that consumed garri-1, fufu-2, and tapioca-3. Explicitly,

$$
\begin{aligned}
\text { Casspdt }= & a_{0}+a_{1} X_{1+} a_{2} X_{2}+a_{3} X_{3}+a_{4} X_{4}+a_{5} X_{5} \\
& +a_{6} X_{6}+a_{7} X_{7}+u_{i} \ldots \ldots \ldots \ldots \ldots \ldots \ldots \ldots \ldots \ldots \ldots \ldots
\end{aligned}
$$

where cassava pdt is cassava product consumed more $($ garri $=1$, fufu $=2$, and tapioca $=3), X_{I}$ is income (Naira), $X_{2}$ is age of the household head (years), $X_{3}$ is cost of cassava product (Naira), $X_{4}$ is cost of close substitute (Naira), $X_{5}$ is household size (number), $X_{6}$ is sex (dummy, male $=1$, female $=0$ ), $X_{7}$ is marital status (singles $=0$, married $=1$ ), $X_{8}$ is education (years), and $U i$ is error term.

The relationship among cassava products (garri, fufu and tapioca) was estimated by the use of Pearson's correlation coefficient analysis $(r)$ specified as shown in equation 3 thus:

$$
r=\frac{n \sum x y-\left(\sum x\right)\left(\sum y\right)}{\sqrt{n\left(\sum x^{2}\right)-\left(\sum x\right)^{2}} \sqrt{n\left(\sum y^{2}\right)-\left(\sum y\right)^{2}}}
$$

where $n$ is the number of pairs of data. The value of $r$ is such that $-1 \leq r \leq+1$. The + and - signs are used for positive linear correlations and negative linear correlations, respectively. 
Table 1: Distribution of respondents according to socioeconomic variables

\begin{tabular}{llcc}
\hline Variables & & Frequency & Percentage (\%) \\
\hline No of observation & & 120 & 100.00 \\
Gender & Male & 55 & 45.83 \\
& Female & 65 & 54.17 \\
Age Range & $<30$ & 42 & 35.00 \\
& $31-40$ & 39 & 32.50 \\
& $41-50$ & 27 & 22.50 \\
Marital Status & $>50$ & 12 & 10.00 \\
& Singled & 46 & 39.33 \\
Household Size & Married & 74 & 61.67 \\
& $<4$ & 41 & 34.17 \\
Educational Level & $>8$ & 61 & 50.83 \\
No formal education & 18 & 15.00 \\
Primary education & & 11 & \\
Secondary education & & 31 & 9.17 \\
Tertiary education & 57 & 25.83 \\
Source of income & & 21 & 47.50 \\
Farming & & 17.50 \\
Trading & 54 & 45.00 \\
Civil servant & 46 & 38.33 \\
Others & 14 & 11.67 \\
\hline Source Field Survey & 6 & 5.00 \\
\hline
\end{tabular}

Source: Field Survey, 2019

\section{RESULTS AND DISCUSSION}

Socio-Economic Characteristics of the Respondents The descriptions of socio-economic characteristics of the household's heads were shown in Table 1 . The results show that many $(54.17 \%$ and $61.67 \%$, respectively) of the respondents were females and are married. This is an indication that the decision of cassava products to consume is manly done by married women. This finding is in agreement with Onyemauwa (2010) that household consumption management in Nigeria is at the concern of women. The result shows that the respondents are young and still active with about $35.00 \%, 32.50 \%, 22.50 \%$ and $10.00 \%$ within the age ranges of $<30,31-40$, 41-50 and $>50$ years, respectively. Ayanwale and Ajetomobi (2001) in their study noted a significant effect of age on household consumption. Half $(50.83 \%)$ of the respondents had a household size in the range of 5-8 persons while $34.17 \%$ and $15.00 \%$ had $<4$ and $>8$ persons, respectively. This implies many mouths to be fed and hence high consumption of cassava products (Theodory et al., 2014). Education is a crucial variable in studying of food demand and consumption (Onyemauwa, 2010). About $47.50 \%$ of the respondents had secondary education, followed by primary education $(25.83 \%)$ and tertiary education (17.50\%).

The result also shows that many $(45.00 \%)$ of the cassava consuming household head were farmers, $38.33 \%$ were traders, $11.67 \%$ were civil servant and $5.00 \%$ were into other occupations. The occupation of the household heads determines the choice of cassava products as cassava farmer have the choice to process cassava roots to any preferred products unlike the civil servant who may consumed the available product in the market.

\section{Expenditure on Cassava Products}

The result in Table 2 shows the distribution of respondents according to amount spent monthly on cassava products. The result indicated that $44.17 \%$, $33.33 \%$ and $22.80 \%$ of the respondents spent between $\$ 1001-\$ 3000$, greater than $\$ 3000$ and less than 1000 respectively in the consumption of cassava products. The result shows fair distribution and moderate spending on cassava products as majority spends within the range $\$ 3000$ on monthly basis. Cassava is mainly widely consumed daily food in many parts of the country. This is in line with Onyemauwa (2010) who noted that the household in Ebonyi State consumed garri at a cost of $\$ 2,500$ monthly representing 5\% of their monthly household income. Obayelu et al. (2011) also observed an average per capita expenditure on food by respondents residing in urban areas of Kogi State as $60.49 \%$ ( $\$ 6,322 /$ month) while it was $57.41 \%$ ( $\$ 3,515.81)$ by the rural households.

\section{Household Consumption of Cassava Products and Its Substitutes}

Figure 1 shows the distribution of the respondents according to the type of cassava product and substitutes consumed in the study area. Majority $(58.80 \%)$ of them consumed garri than pounded cassava fufu $(28.70 \%)$, tapioca $(7.5 \%)$ and cassava chip and flour $(2.5 \%$ each). The result also shows that many $(41.30 \%)$ of the respondents indicated rice as their close substitute to cassava product (garri). About $24 \%$ and $20 \%$ of them indicated yam and beans, respectively as substitutes to cassava product, whereas potato and plantain had an equal $(7.50 \%)$ distribution as substitutes to garri. This shows that most of the households consumed garri more than other cassava products. This may be due to availability of the product in the study area. This finding is consistent with the assertion that garri is the most important processed cassava roots among many households (Onyemauwa, 2010). The low score of tapioca as cassava product consumed in the study area may be as a result of cultural influence (least regarded as a main meal but as dessert). Again, abacha and cassava flour had the lowest consumption percentage which may be due the eating habit and menu in the locality of the respondents. They consumed more of rice than other substitutes and probably will spend more percentage of household monthly income on that relative to cassava products.

Table 2: Distribution of respondents according to monthly expenditure on cassava products (garri)

\begin{tabular}{lll}
\hline $\begin{array}{l}\text { Monthly expenditure on } \\
\text { cassava product ( })\end{array}$ & Frequency & Percentage (\%) \\
\hline$<1000$ & 27 & 22.50 \\
$1001-3000$ & 53 & 44.17 \\
$>\quad 3000$ & 40 & 33.33 \\
Total & 120 & 100.00 \\
\hline
\end{tabular}

Source: Field Survey, 2019 


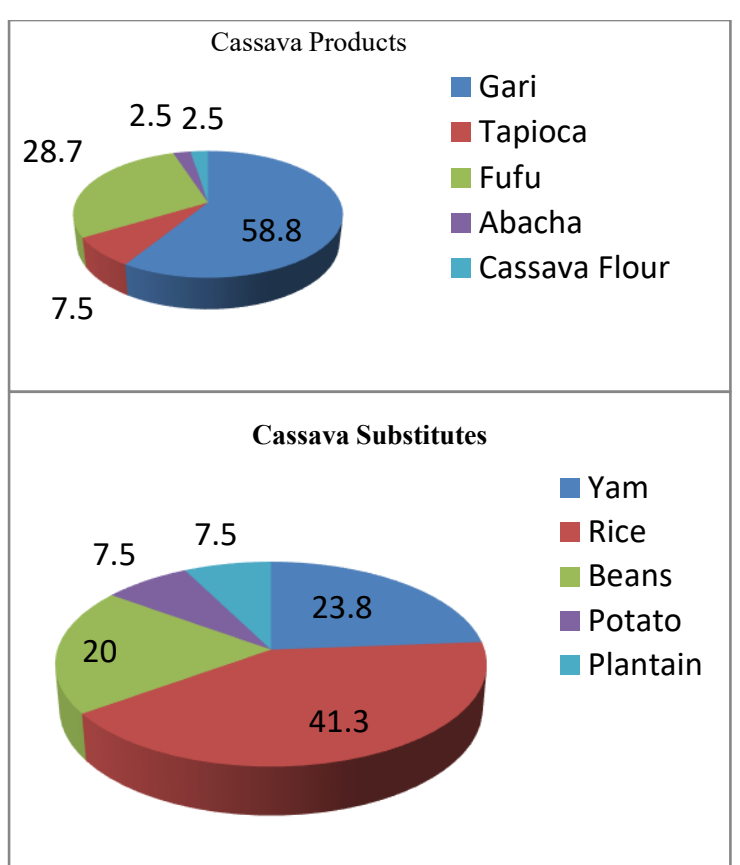

Figure 1: Distribution of respondents according to cassava product and its substitutes consumed

Source: Field Survey, 2019

\section{Reasons for Preference of Cassava Products Consumption}

In determining the reasons for cassava products preference, three highest consumed cassava products identified in the study area were discussed in Table 3. The result in Table 3 shows the factors determining the preference of cassava product consumption among the households in the study area. The findings show that $73.75 \%, 57.50 \%$ and $45.00 \%$ of the respondents preferred garri over other cassava products as the factors of household choice, nutritional value and availability, respectively. Also, about $32.50 \%, 25.00 \%, 20.00 \%$ and $18.75 \%$ of the respondents indicated preference of garri as factors of health status, cost of the product, method of preparation and taste respectively. The result also shows that about $47.50 \%$ of the respondents preferred tapioca over other products as a result of ease of preparation while $35.00 \%$ each indicated availability of the product and health status as reasons for consumption. About $22.50 \%, 16.25 \%, 10.00 \%$ and $3.75 \%$ of the household also preferred tapioca over other cassava products as the factors of cost of the product, household choice, taste and nutritional value respectively. Nevertheless, the result shows that the respondents preferred fufu to other cassava products as factors of cost of the products $(52.50 \%)$, taste $(46.25 \%)$, and nutritional value $(38.75 \%)$, method of preparation $(32.50 \%)$, availability $(20.00 \%)$ and household size $(10.00 \%)$. Mofu (2013) noted on his study on determinant of behavioural factors for cassava consumption among adults in Southern Zambia, that heath status and nutritional values were main factors for choosing cassava products over another.

\section{Determinants of Choice of Cassava Products Consumption}

Table 4 shows the ordered Probit regression for factors influencing the choice of consumption of cassava products in the study area. The ordered Probit model of cassava consumption yielded intuitive results. The non-zero censoring points were of positive signs, with the lower censoring threshold at 0.77 cassava consumed products and the upper threshold at 1.80 cassava products consumed, each statistically significantly different from zero. The goodness of fit measured by the $\chi^{2}$ showed that the choice of explanatory variables included in the ordered Probit model explained the variation in choice of cassava product consumption. The likelihood ratio tests indicate that the slope coefficients were significantly different from zero. The result shows that out of eight explanatory variables fitted in the consumption model, four were statistically significant and thus discussed.

The results show that coefficient for age was negative and significantly related to choice of cassava products consumption at 5\% level of probability. This implies that households that are relatively of young members are more likely to consume more of tapioca other than garri (or fufu). This is probably because of ease of preparation and processing of tapioca as indicated in the reason for preference than the complex and rigorous nature of garri and fufu. The previous research effort of Ayanwale and Ajetomobi (2001) showed that age was positive and significantly influenced the level of household consumption of cassava products. Cassava root and marital status had significant $(p<$ 0.05 ) positive and negative relationships with choice of cassava product consumption, respectively. Thus, decrease in cost of cassava roots will likely increase garri consumption over tapioca or fufu. This is expected as people tend to go for products that will serve as meal and at a reasonable price. Again, those who are married are likely to consume more of garri than tapioca or fufu indicating that the married couples will go for products that are acceptable by other members of the family especially the children. In terms of processing, married households have advantage over the singles as the spouse and children will assist in processing of cassava root to garri. Onyemauwa (2010) observed that the married households had positive impact on agricultural production and economic growth of farm household in terms of labour provision. The coefficient for household size was significant at $1 \%$ level and was positively related to choice of cassava product consumption in the study area. Increase in household size in the area will likely increase consumption of garri other than tapioca or fufu. Household's size played a very important role in choosing the cassava product for consumption (Theodory et al., 2014) and quantity of consumption (Tomlins et al., 2007). 
Table 3: Factors determining the preference of cassava products consumption

\begin{tabular}{|c|c|c|c|}
\hline \multirow[t]{2}{*}{ Factors } & \multicolumn{3}{|c|}{ Percentage } \\
\hline & Garri & Tapioca & Fufu \\
\hline Cost of the product & $25.00(20)$ & $22.50(18)$ & $52.50(42)$ \\
\hline Taste & $18.75(15)$ & $10.00(8)$ & $46.25(37)$ \\
\hline Preparation/Method of Processing & $20.00(16)$ & $47.50(38)$ & $32.50(26)$ \\
\hline Availability & $45.00(36)$ & $35.00(28)$ & $20.00(16)$ \\
\hline Nutritional Value & $57.50(46)$ & $3.75(3)$ & $38.75(31)$ \\
\hline Household Choice & $73.75(59)$ & $16.25(13)$ & $10.00(8)$ \\
\hline Health Status & $32.50(26)$ & $35.00(28)$ & $0.00(0)$ \\
\hline
\end{tabular}

Multiple Responses; Source: Field Survey, 2019. Figures in parenthesis are the frequencies.

Table 4: Ordered Probit regression for factors influencing the choice of consumption of cassava products in the study area

\begin{tabular}{lcccc}
\hline Variable & Parameter & Coefficient & Standard Error & Z-test \\
\hline Income (Naira) & $\mathrm{X}_{1}$ & 0.2228 & 0.28660 & 0.78 \\
Age (years) & $\mathrm{X}_{2}$ & -0.3769 & 0.1771 & $-2.13^{* *}$ \\
Cost of cassava root (Naira) & $\mathrm{X}_{3}$ & -0.4518 & 0.1995 & $-2.26^{* *}$ \\
Expenditure on substitute (Naira) & $\mathrm{X}_{4}$ & -0.2089 & 0.2061 & -1.01 \\
Household size (dummy) & $\mathrm{X}_{5}$ & 0.6624 & 0.1576 & $4.20^{* * *}$ \\
Sex (dummy) & $\mathrm{X}_{6}$ & -0.0349 & 0.2684 & -0.13 \\
Marital status (dummy) & $\mathrm{X}_{7}$ & 0.8071 & 0.3847 & -0.11 \\
Level of education (years) & $\mathrm{X}_{8}$ & -0.0174 & 0.1534 & $3.1942^{* * *}$ \\
Ancillary Parameters & & & & $2.1059^{* *}$ \\
Cut 1 & & 0.7730 & 0.2420 & \\
Cut 2 & & 1.8031 & 0.8562 & \\
Log likelihood & & -68.204791 & & \\
$\chi^{2}$ & & 0.0012 & & \\
Pseudo R & & 0.4240 & & \\
Number of observations & & &
\end{tabular}

\section{Determination of the Marginal Effects}

To augment the interpretation of the estimated results presented in Table 4, the marginal effects of each variable on the predicted probability of consuming cassava products is evaluated as the means of the explanatory variables, are presented in Table 5. The marginal effects report of the ordered Probit regression provides the probability that the household will consume a particular cassava product more than the other. The result provides the probability estimation for the likelihood of household cassava consumption given the statistically significant variables. The results of the marginal effect of the ordered Probit regression indicates that there is an increase in probability of garri consumption by $14.57 \%, 17.46 \%, 3.11 \%$ and $24.65 \%$ if there is an decrease in age by one year, decrease in cost of cassava root by one Naira, increase in household size by one person and increase in married household by one unit respectively. The result also shows that fufu consumption will increase if there is a probability of $7.96 \%, 9.54 \%, 1.70 \%$ and $13.96 \%$ decrease in age by one year and increase in cost of cassava root by one Naira, household size by one person and married household head by one respectively. Also, consumption of tapioca will increase by $6.61 \%$ if there is a one-year increase in age, $7.92 \%$ if there is one Naira increase in cost of cassava root, $1.41 \%$ if households increase by one person and $10.68 \%$ if married household reduce by one.
Table 5: Marginal effects for continuous determinants

\begin{tabular}{lccc}
\hline \multirow{2}{*}{ Variables } & \multicolumn{3}{c}{ Dy/Dx } \\
\cline { 2 - 4 } & Cut 1 & Cut 2 & Cut 3 \\
\hline Age & -0.1457 & -0.0796 & 0.0661 \\
cost of cassava root & -0.1746 & 0.0954 & 0.0792 \\
Household size & 0.0311 & 0.0170 & 0.0141 \\
Marital status & 0.2465 & 0.1396 & -0.1068 \\
\hline Source: Field Survey, 2019
\end{tabular}

Source: Field Survey, 2019

Table 6: Correlation coefficient of relationship among cassava products consumption

\begin{tabular}{|c|c|c|c|}
\hline & Garri & Fufu & Tapioca \\
\hline Gari & 1.0000 & & \\
\hline Fufu & -0.1336 & 1.0000 & \\
\hline Tapioca & 0.0278 & $-0.8855^{*}$ & 1.000 \\
\hline
\end{tabular}

Relationships in Cassava Products Consumption

The result in Table 6 shows the correlation analysis of relationship among consumption of cassava products in the study area. The results shown that there is a negative and significant $(r=0.8855)$ correlation between tapioca and fufu at 5\% level of probability. This implies that there is a weak and indirect relationship between consumption of tapioca and fufu. It further implies that increase in fufu consumption will lead to a decrease in tapioca consumption in the study area by $88.55 \%$ and vice versa. This is as expected since fufu is heavy and can be eaten as the main meal while tapioca is mainly consumed as appetizer with coconut or groundnut not main meal. The result also shows a negative correlation $(-0.1336)$ between fufu and garri and positive correlation (0.0278) between tapioca and garri although not significant. 
CONCLUSION AND RECOMMENDATION

The study provided empirical evidence on the household consumption behaviour of cassava products in Ebonyi State, Nigeria. The study confirmed the findings of previous empirical studies to an extent on factors that influence consumption of cassava products especially on effect of household size and cost of the product. The ability of the households to consume or prefer a particular cassava product to another is a function of many factors as estimated and observed by the study. Using data from the field survey, the study has found out that consumption of cassava products in the area is influenced by age, cost of cassava product, household size and marital status. The study found garri, pounded cassava and tapioca as the three major cassava products consumed, while rice, yam and beans as the three major garri sub statutes consumed by the respondents in the area. The respondents preferred cassava products over another as a result of cost of products, tastes, method of preparation, availability, nutritional value, choice and health status. The study therefore recommended for policy that will effectively promote cassava product consumption should be lay emphasis on the adult population and household size.

\section{REFERENCES}

Arua R.N. (2019). Value chain analysis of cassava derivatives in South East, Nigeria. PhD Thesis Submitted to the Department of Agricultural Economics, University of Nigeria Nsukka, Nigeria, $156 \mathrm{pp}$.

Ayanwale A.B. and Ajetomobi J.O. (2001). Determinants of urban households demand for cassava and cassava products in Kaduna, Northern Nigeria. Nig. J. Agric. Prod., 28 (1), 98-102
Barnett W. (2003). The modern theory of consumer behavior: ordinal or cardinal? The Quarterly J. Austr. Econ., 6 (1), 41-65

Ezeh C.I., Obioma N.Q. and Onuabuobi J.C. (2011). Consumer behaviour and preferences to cassava value added products in Ikwuano Local Government Area (L.G.A) of Abia State. Nig. Int. J. Soc. Sci. Human., 1 (4), 274-277

Greene W.H. (2003). Economic Analysis, $5^{\text {th }}$ ed. Prentice Hall, New Jersey, 828 pp.

Mofu M.J. (2013). Determinant behavioural factors for cassava consumption among adults in Southern Zambia. J. Nutr. Food Sci., 3 (3), 27-34

Nweke F.I., Hahn S.K. and Ugwu B.O. (2002). Circumstances of rapid spread of cultivation of improved cassava varieties in Nigeria. J. Farm. Sys. Res. Ext., 49 (3), 251-269

NPC (2015). Estimated population figures. National Population Commission, Nigeria

Obayelu A.E., Okoruwa V.O. and Ajani O.I.Y. (2011). Analysis of differences in rural-urban households food expenditure share in Kwara and Kogi States of Nigeria. Glob. J. Agric. Sci., 10 (1), 1-18

Ogunniyi L.T. (2011). Household consumption pattern of cassava products in Oyo State. J. Sci. Front. Res., 11 (6), 2249-2260

Onyemauwa C.S. (2010) Analysis of household consumption of cassava products in Ohaozara, Ebonyi State, Southeast Nigeria. Res. J. Agric., 2 (6), 1-6

Theodory M., Honi B. and Sewando P. (2014). Consumer preference for cassava products versus different processing technologies. Int. J. Innov. Sci. Res., 2 (1), 143-151

Tomlins K., Sanni L., Oyewole O. et al. (2007). Consumer acceptability and sensory evaluation of a fermented cassava product (Nigerian fufu). J. Sci. Food Agric., 87, 1949 - 1956 